\title{
A SYBR Green I based real time RT-PCR assay for specific detection and quantitation of Peste des petits ruminants virus
}

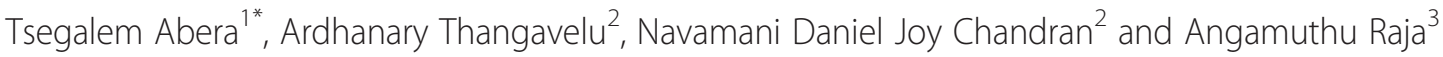

\begin{abstract}
Background: Peste des petits ruminants (PPR) is an economically important disease of small ruminants such as sheep and goats. The disease is characterized by severe pyrexia, oculo-nasal discharge, pneumonia, necrosis and ulceration of the mucous membrane and inflammation of the gastro-intestinal tract leading to severe diarrhea. A SYBR Green I based real time RT-PCR targeting the N gene of PPRV has not been established for PPRV detection. Thus, the objective of present study was to develop highly sensitive N gene target SYBR Green I real time RT-PCR for specific detection and quantification of PPRV in clinical samples. A set of primers was designed to detect the nucleocapsid (N) gene of PPRV.

Results: The assay exhibited high specificity as all the viruses which have clinical and structural similarities to PPRV including Canine distemper virus (CDV), Measles virus (MV), Bluetongue virus (BTV) and Newcastle disease virus (NDV) failed to show an amplification signal. The lower detection limit of the assay was 5.11 copies/ $\mu$ l (Ct value of $33.67 \pm 0.5$ ) and $0.001 \mathrm{TCID}_{50} / \mathrm{ml}$ (Ct value of $34.7 \pm 0.5$ ) based on plasmid copy number and tissue culture infectivity titre. The assay was $3-\log$ more sensitive than the conventional RT-PCR. The coefficient of variation (CV) values for intra- and inter-assay variability were low, ranging from $0.32 \%-2.31 \%$, and $0.71 \%-5.32 \%$, respectively. To evaluate the performance of the newly developed assay, a total of 36 clinical samples suspected of PPR were screened for the presence of PPRV in parallel with conventional RT-PCR. The real time RT-PCR assay detected PPRV in $30(83.3 \%)$ of clinical samples compared to $16(44.4 \%)$ by conventional RT-PCR.
\end{abstract}

Conclusions: The two-step SYBR Green I based real time RT-PCR assay reported here is highly sensitive, specific, reproducible and rapid for detection and quantification of PPRV nucleic acids.

Keywords: SYBR Green I, Real time RT-PCR, N gene, PPRV, Detection, Quantitation

\section{Background}

Peste des petits ruminants (PPR) is an economically important disease of small ruminants such as sheep and goats. The disease is characterized by severe pyrexia, oculo-nasal discharge, pneumonia, necrosis and ulceration of the mucous membrane and inflammation of the gastrointestinal tract leading to severe diarrhea [1].

The causative agent of this disease, peste des petits ruminants virus (PPRV), is a member of the Morbillivirus genus in the Paramyxoviridae family. It has a negative sense single-stranded RNA genome encoding eight proteins [2].

\footnotetext{
* Correspondence: tsegalem.abera@gmail.com

${ }^{1}$ College of Veterinary Medicine, Jigjiga University, Jijiga, Ethiopia

Full list of author information is available at the end of the article
}

The $\mathrm{N}$ gene of morbilliviruses is the most expressed gene due to a transcriptional gradient from the $3^{\prime}$ to the $5^{\prime}$ end of the genome and it is also well-conserved gene [3]. Thus, this gene is probably the best target for the development of a highly sensitive detection method.

Several conventional reverse transcription polymerase chain reactions (RT-PCRs) are available for detection of PPRV genomic material [4-6]. However, these conventional RT-PCR assays are labor intensive, as they require gel analysis for the detection of PCR products with a consequent high risk of contamination [7].

Real time RT-PCR has gained wider acceptance over conventional RT-PCR because it is more rapid, sensitive and reproducible. Few real time RT-PCR assays have been described for detection and quantification of PPRV

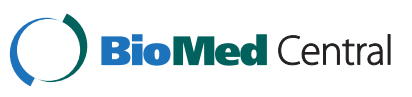


in clinical samples using TaqMan chemistry [7-10]. In comparison with TaqMan-PCR, SYBR Green I based realtime RT-PCR assay has the advantages of being more cost-effective, easy to design, more precise and produced a more linear decay plot [11].

A single report described SYBR Green I based realtime RT-PCR assay targeting the $\mathrm{M}$ gene for detection of PPRV in clinical samples [12]. However, a SYBR Green I based real time RT-PCR targeting the $\mathrm{N}$ gene of PPRV has not been established for PPRV detection. In the present study, we developed highly sensitive $\mathrm{N}$ gene target SYBR Green I real time RT-PCR for specific detection and quantification of PPRV in clinical samples.

\section{Methods}

\section{Viruses, cells and clinical samples}

The different viruses used in this study are listed in Table 1. Vero cell adapted PPRV Coimbatore (CBE) field isolate, maintained in the Department of Veterinary Microbiology, Madras Veterinary College, Chennai 600007 , was used throughout this study to standardize the realtime RT-PCR assay. Viruses which have structural and/or clinical similarities to PPRV were included to test the specificity of the developed assay. Vero cells were used for virus propagation and titration. A total of 36 field samples, from PPR suspected outbreaks in different areas of the Indian state of Tamil Nadu, submitted to the Department of Veterinary Microbiology, Madras Veterinary College for diagnosis were analyzed. Samples received for analyses from different vet clinics were ocular, nasal, oral and rectal swabs, spleen, kidney, lung, lymph nodes and dung.

\section{Viral RNA extraction and cDNA synthesis}

Viral RNA was extracted from tissue culture supernatant using QIAamp ${ }^{\ominus}$ Viral RNA Mini Kit (Qiagen ${ }^{\bullet}$, Germany), following manufacturer's instructions. Trizol reagent (Invitrogen, CA, USA) was also used to isolate RNA from clinical samples. Synthesis of cDNA was carried out in $20 \mu \mathrm{l}$ reaction using RevertAid ${ }^{\mathrm{Tm}} \mathrm{H}$ minus first Strand cDNA Synthesis kit (Fermentas, USA) following manufacturer's instructions. Briefly, $11 \mu \mathrm{l}$ of the purified RNA were added to a mixture containing $4 \mu \mathrm{l}$ RT buffer $(5 \times), 1 \mu \mathrm{l}$ of random hexamer, $2 \mu \mathrm{l} 10 \mathrm{mM}$ dNTP, $1 \mu \mathrm{l}$ RNase inhibitor and $1 \mu \mathrm{l}$ of Moloney murine leukemia virus reverse transcriptase. The reaction was carried out at $25^{\circ} \mathrm{C}$ for $5 \mathrm{~min}, 42^{\circ} \mathrm{C}$ for $60 \mathrm{~min}$ and $70^{\circ} \mathrm{C}$ for $5 \mathrm{~min}$ and stored at $-40^{\circ} \mathrm{C}$ until use.

\section{Primer design and synthesis}

A set of primer was designed according to the sequences of nucleocapsid protein $(\mathrm{N})$ gene (GenBank accession no. GQ452013.1) of PPRV Sungri-96 strain by using Fast PCR software. The designed primers (Forward $\mathrm{N}_{2} \mathrm{~F}$ : $5^{\prime}$ GACGGCAT CAGGTTCAGGAG-3' (57-76) and Reverse $\mathrm{N}_{2} \mathrm{R}$ : 5'-GCCAAT CTGACAAGCCTGTC G-3' (156-177) were validated by OligoAnalyzer1.2 and synthesized commercially (Sigma Aldrich, Bangalore, India). The amplified cDNA fragment using primer pair $\mathrm{N}_{2} \mathrm{~F}$ / $\mathrm{N}_{2} \mathrm{R}$ was expected to be 121 base pairs (bp) in length.

\section{Real time RT-PCR}

The RT-PCR assay was performed on a Realplex ${ }^{4}$ real time PCR machine (Eppendorf, Germany) using SYBR premix Ex Taq, (TaKaRa Bio Inc., Japan). The assay was carried out in a total volume of $10 \mu \mathrm{l}$ reaction mixture containing $5 \mu \mathrm{l}$ of $2 \mathrm{x}$ SYBR Premix Ex Taq master mix, $1.5 \mu \mathrm{l}$ of cDNA, $1 \mu \mathrm{l}(10 \mu \mathrm{M})$ of each primer and $2.5 \mu \mathrm{l}$ nuclease free water. The optimized cycling conditions were as follows: initial denaturation at $94^{\circ} \mathrm{C}$ for $5 \mathrm{~min}$, followed by 40 cycles of denaturation at $94^{\circ} \mathrm{C}$ for $30 \mathrm{sec}$, primer annealing at $52^{\circ} \mathrm{C}$ for $30 \mathrm{sec}$, and extension at $72^{\circ} \mathrm{C}$ for $30 \mathrm{sec}$. The fluorescence was measured at the end of each cycle. A melt curve analysis was performed following amplification to verify the specificity of the amplified products. Melting curve analysis consisted of $70^{\circ} \mathrm{C}$ for $15 \mathrm{sec}$, and followed by temperature increase to $95^{\circ} \mathrm{C}$ for $15 \mathrm{sec}$ at the rate of $1.25^{\circ} \mathrm{C}$ per sec with continuous reading of fluorescence.

\section{Table 1 Viruses used in the study}

\begin{tabular}{|c|c|c|}
\hline Virus & Strain & Source \\
\hline \multirow[t]{5}{*}{ Peste des petits ruminants virus (PPRV) } & AR 87 vaccine strain & Dept. of Vet. Microbiology, Madras Veterinary College \\
\hline & Sunguri vaccine strain & Indian Immunologicals Ltd, Bangalore \\
\hline & Coimbatore vaccine strain & Dept. of Animal Biotechnology, Madras Veterinary College \\
\hline & Coimbatore field isolate & Dept. of Vet. Microbiology, Madras Veterinary College \\
\hline & Recent field isolates & Dept. of Vet. Microbiology, Madras Veterinary College \\
\hline Canine distemper virus (CDV) & Vaccine strain & Nobivac Puppy DP, Intervet \\
\hline Measles virus (MV) & Vaccine strain & Serum institute of India LTD, Pune \\
\hline Bluetongue virus (BTV) & Vaccine strain & Dept. of Vet. Microbiology, Madras Veterinary College \\
\hline Newcastle disease virus (NDV) & D58 & Dept. of Vet. Microbiology, Madras Veterinary College \\
\hline
\end{tabular}




\section{Conventional RT-PCR}

For comparative purpose, conventional RT-PCR was performed on the cDNA preparations of the PPRV with a primer set of NP3 (5'-TCTCGGAAATC GCCTCACA GACTG-3') and NP4 (5'-CCTCCTCCTGGTCCTCC AG AATCT-3') as described by Couacy-Hymann et al., [5], which yielded 351 bp of PCR product. Each reaction tube of $20 \mu \mathrm{l}$ contained $10 \mu \mathrm{l}$ Taq DNA Pol 2.0x Master Mix Red (Biomol, Denmark), $1 \mu \mathrm{l}(10 \mathrm{M})$ of each primer, $3 \mu \mathrm{l}$ of cDNA and $5 \mu \mathrm{l}$ of nuclease free water (Genei ${ }^{\mathrm{Tm}}$, Bangalore, India). The mixture was subjected to an initial denaturation at $95^{\circ} \mathrm{C}$ for $5 \mathrm{~min}$ followed by 35 cycles of denaturation at $94^{\circ} \mathrm{C}$ for $30 \mathrm{~s}$, annealing at $55^{\circ} \mathrm{C}$ for $30 \mathrm{~s}$ and extension at $72^{\circ} \mathrm{C}$ for $7 \mathrm{~min}$. Amplification of target sequences was performed in a 2720 thermal cycler (Applied Biosystems). Amplification products $(8-10 \mu \mathrm{l})$ were resolved on $1.5 \%$ agarose gel and stained with ethidium bromide for visualization.

\section{Generation of quantification standards}

A fragment of $488 \mathrm{bp}$ of $\mathrm{N}$ gene of PPRV containing the real time RT-PCR primers binding sites were amplified using the primer pair $\mathrm{N}_{3} \mathrm{~F}$ (forward primer): $5^{\prime}$-CAAAGC GCCGA CGGCA TCA GGTT-3' (48-70) and $\mathrm{N}_{3} \mathrm{R}$ (reverse primer): 5-'GCCAGAAGGATCCAGACTTGTGC3' (514-536) (In house designed). The RT-PCR product was cloned into RBC T\&A cloning vector (RBC Biosciences) according to the manufacturer's instructions. Plasmid DNA was recovered from the transformed Escherichia coli BL-21 cells using AxyPrep Plasmid Miniprep Kit (Axygen Biosciences). The OD value of the plasmid DNA standard concentrations was measured at $260 \mathrm{~nm} / 280 \mathrm{~nm}$ on Thermo Scientific NanoDrop ${ }^{\text {TM }} 1000$ Spectrophotometer (NanoDrop Technologies, LLC, Wilmington, DE, USA).
Plasmid copy number was calculated using the formula described by Adams [13].

\section{Specificity and sensitivity of the real time RT-PCR}

The specificity of the developed assay was assessed against viral nucleic acid extracted from a range of animal viruses of clinical and structural relevance to PPRV. To check the sensitivity of the assay, PPRV CBE strain was titrated on Vero cells in a 96-well micro titre plate using standard cell culture procedure and the virus titre was calculated using Reed and Muench [14] formula. PPRV having a titre of $10^{5} \mathrm{TCID}_{50} / \mathrm{ml}$ was diluted 10 -fold serially from $10^{\wedge}-1$ to $10^{\wedge}-11$, and total RNA was extracted from each dilution, subsequently cDNA synthesis was performed. The synthesized cDNA was analyzed by newly developed two-step real-time PCR assay and simultaneously with conventional PCR to allow better comparison of the analytical sensitivity. Additionally, the sensitivity of the assay was determined by running 10 -fold serial dilutions $\left(5.11 \times 10^{7}\right.$ to $5.11 \times 10^{0}$ copies $\left./ \mu \mathrm{l}\right)$ of the plasmid standard in duplicates.

\section{Reproducibility}

To evaluate reproducibility of the assay, the DNA standard ranging from $5.11 \times 10^{7}$ copies $/ \mu$ lo $5.11 \times 10^{0}$ copies/ $\mu$ l was tested repeatedly. Three separate dilution series were assayed in a single run to evaluate intra-assay variations. Whereas, the inter-assay variations were measured by testing each dilution in three separate consecutive runs. The mean, standard deviation (SD) and coefficient of variation $(\mathrm{CV})$ for both intra-assay and inter-assay variations were calculated separately for each standard DNA dilution based on their Ct values using Microsoft Excel software.

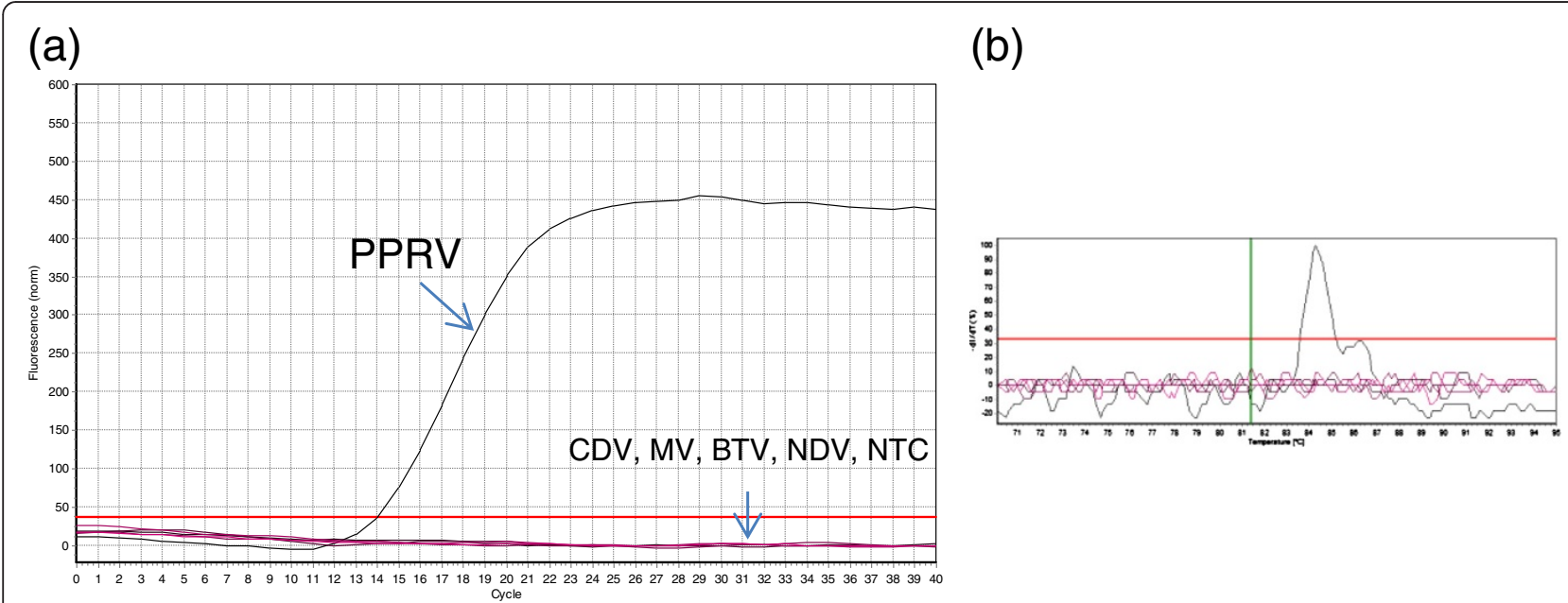

Figure 1 Specificity of $\mathbf{N}$ gene based real time RT-PCR. (a) amplification plot representing PPRV, CDV, MV, BTV, NDV and No template control (NTC). (b) Melting curve analysis. 


\section{Spiking}

To check the performance of the newly developed assay, clinical samples (2 nasal swabs from goats) were spiked with known titre of PPR virus as described by Balamurugan et al. [8]. Infected cell culture fluid containing $10^{5}$ $\mathrm{TCID}_{50} / \mathrm{ml}$ viruses was diluted 1: 10 serially by using the two negative nasal swabs as diluent. The $10^{3}$ and $10^{4} \mathrm{TCID}_{50} / \mathrm{ml}$ spiked titre viruses were used for total RNA extraction. Control virus samples $\left(10^{3}\right.$ and $10^{4}$
$\mathrm{TCID}_{50} / \mathrm{ml}$ titre virus suspensions) were also used for RNA extraction.

\section{Ethical committee approval}

Since we did not perform any trial by keeping experimental animals, ethical committee approval is not required as per our Institutional ethical committee. It means such work is ethically approved one which does not require specific submission of proposal and approval. TANUVAS Institutional

(a)

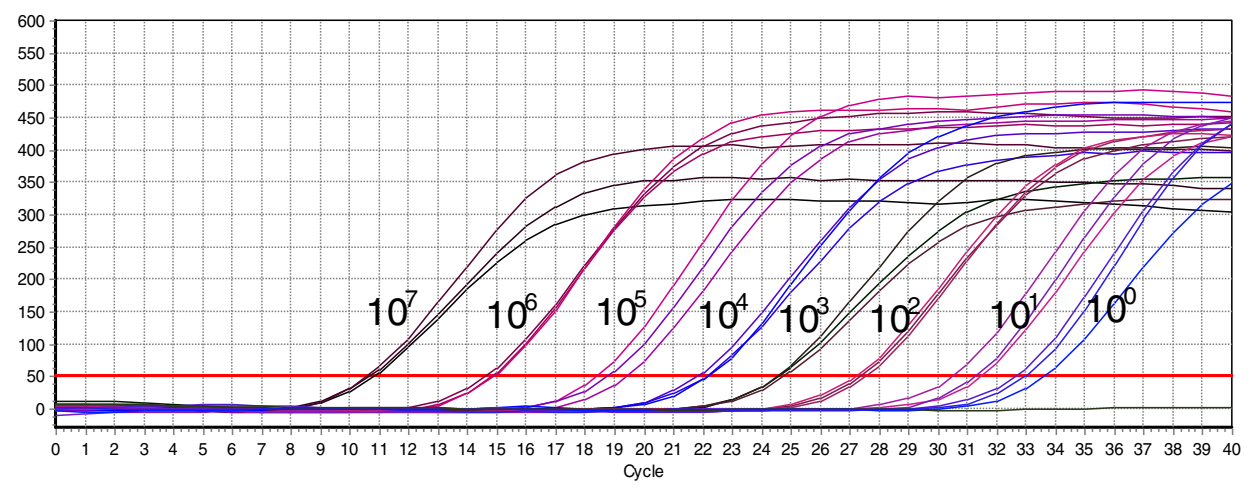

(b)

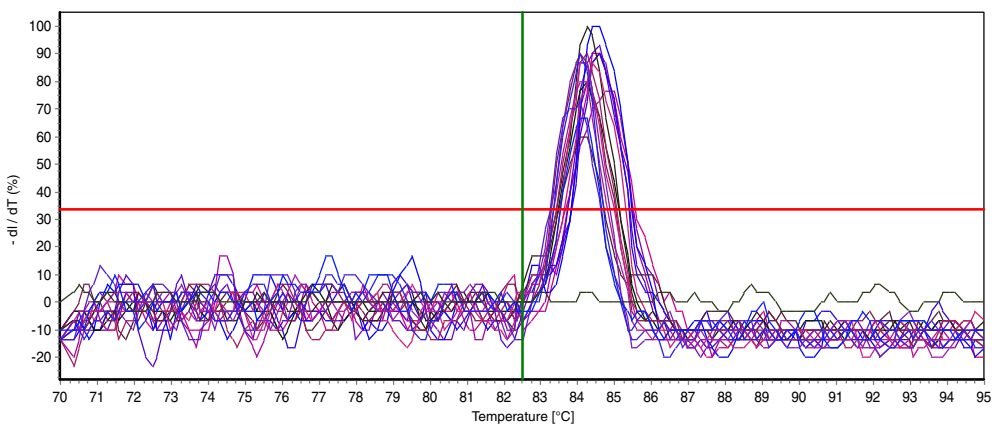

(c)

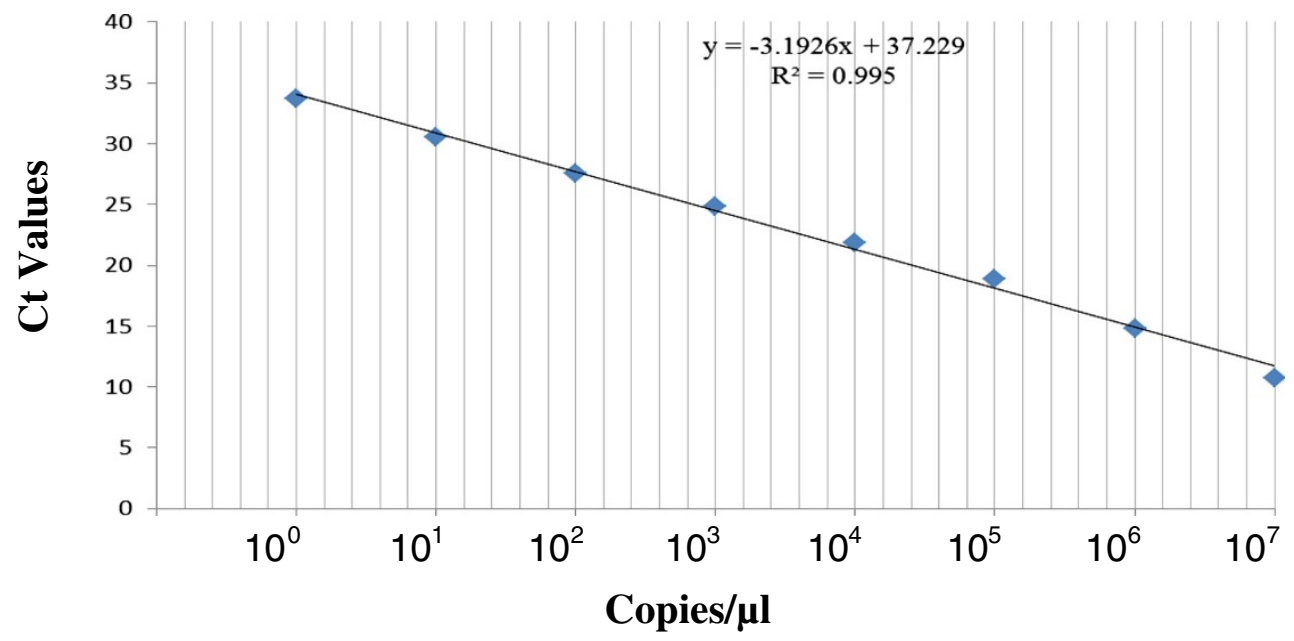

Figure 2 The detection limit and standard curve of real time RT-PCR assay based on plasmid copy number. (a) Amplification plot of 10 -fold serial diluted plasmid DNA ranging from $5.11 \times 10^{7}$ to $5.11 \times 10^{\circ}$ copies $/ \mu l$. (b) Melting curve analysis. (c) Standard curve. 
Animal Ethical Committee Registration number is: No.190/ CPCSEA/dated 22.05.2000. Our research work was approved by Institutional Biosafety Committee in its II meeting of the year 2011 dated 21.10.2011.

\section{Results}

\section{Generation of standard curve}

The concentration of the plasmid DNA was $176.2 \mathrm{ng} / \mu \mathrm{l}$, which equates $5.11 \times 10^{10}$ copies $/ \mu \mathrm{l}$. A series of 10 -fold dilutions starting from $5.11 \times 10^{7}$ to $5.11 \times 10^{\circ}$ were prepared. The correlation between the plasmid dilutions and the threshold cycle $(\mathrm{Ct})$ values in real time RT-PCR were analyzed by plotting a standard curve. A linear regression relationship was observed with a coefficient of determination $\left(R^{2}\right)$ of 0.995 , a slope of -3.1926 and a reaction efficiency of $105 \%$. The generated standard curve covered a linear range of seven orders of magnitude and showed linearity over the entire range of quantification.

\section{Specificity}

Melting peaks analysis on the PCR products of plasmid DNA standard and 10-fold serially diluted tissue culture infected PPR virus showed that there were no primerdimers and non-specific products. Only a single peak was visible in the melting peak chart. Specific amplification of the PPRV target sequence was identified by the generation of a melt peak at $84.31 \pm 0.20$. Specific amplification signal was found on available PPRV strains (Arasur, Sunguri, Coimbatore and recent field isolates). Additionally, the assay also exhibited specificity as an amplification signal was observed only with PPRV nucleic acid. None of the viruses (CDV, MV, BTV, and NDV) and no template control (NTC) showed an amplification signal (Figure 1).

\section{Detection limit}

The lower detection limit, based on plasmid copy number, achieved was 5.11 copies/ $\mu$ l with a corresponding $\mathrm{Ct}$ value of $33.67 \pm 0.5$ (Figure 2). At the same time, by using the same real time RT-PCR primer set in conventional RT-PCR the lower detection limit was found to be $5.11 \times 10^{1}$ copies/ $\mu$ l (Figure 3 ). Further, the sensitivity of the assay was also evaluated by testing 10 -fold serial dilutions of PPR virus having a titre of $10^{5} \mathrm{TCID}_{50} / \mathrm{ml}$. The assay could detect down to $0.001 \mathrm{TCID}_{50} / \mathrm{ml}$ with corresponding $\mathrm{Ct}$ value of 34.7 (Figure 4).

\section{Comparison of SYBR Green I real time RT-PCR and conventional RT-PCR}

The detection limit of newly developed $\mathrm{N}$ gene based real time RT-PCR assay was compared with already established $\mathrm{N}$ gene based conventional RT-PCR assay (Couacy-Hymann et al. [5] by using a 10-fold serial dilutions of PPRV having a titre of $10^{5} \mathrm{TCID}_{50} / \mathrm{ml}$. The lower detection limit for SYBR Green I real time RT-PCR was found to be $0.001 \mathrm{TCID}_{50} / \mathrm{ml}$. However, the conventional RT-PCR assay (which amplified $351 \mathrm{bp}$ ) was able to detect $1 \mathrm{TCID}_{50} / \mathrm{ml}$ (Figure 5). The SYBR Green I real time RT-PCR assay was found to be 1000 times more sensitive than conventional RT-PCR assay.

\section{Reproducibility}

Reproducibility of the assay was assessed based on the $\mathrm{Ct}$ values obtained from testing DNA standard in triplicates. The intra-assay reproducibility of the assay was analyzed by using 10 -fold dilutions of the plasmid DNA standard ranging from $5.11 \times 10^{7}$ to $5.11 \times 10^{0}$ copies $/ \mu \mathrm{l}$ in triplicates per run. The calculated SD and $C V$ values were, ranging from 0.10 to 0.58 and from $0.32 \%$ to $2.31 \%$, respectively [Table $2(\mathrm{a})$ ]. Whereas, the inter-assay

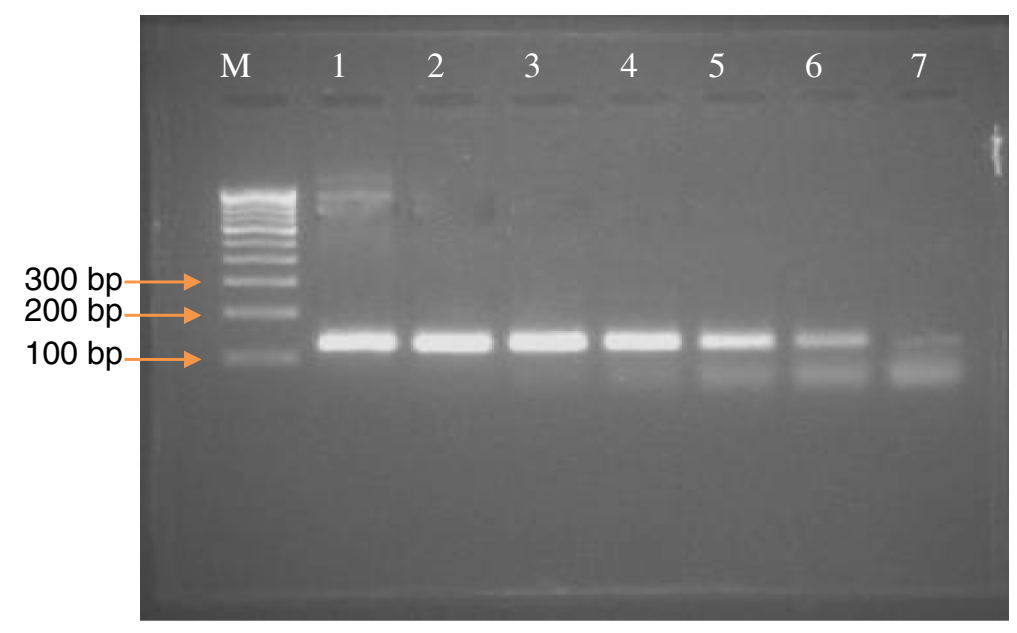

Figure 3 Sensitivity based on plasmid copy number by using $\mathbf{N}_{2} \mathbf{F} / \mathbf{N}_{\mathbf{2}} \mathbf{R}$ primer pairs. M-100 bp DNA ladder; Lane-1, $2.88 \times 10^{7}$; Lane-2,

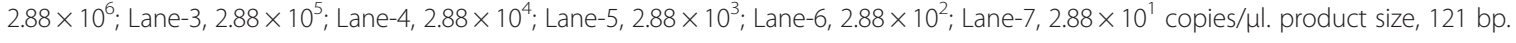


(a)

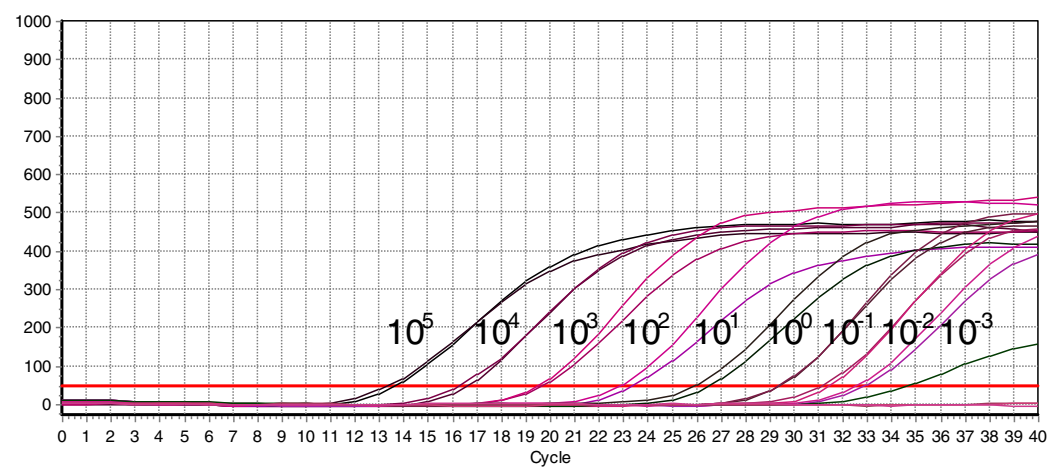

(b)

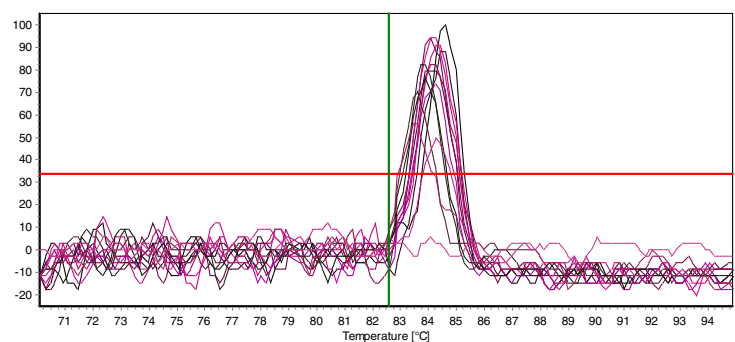

(c)

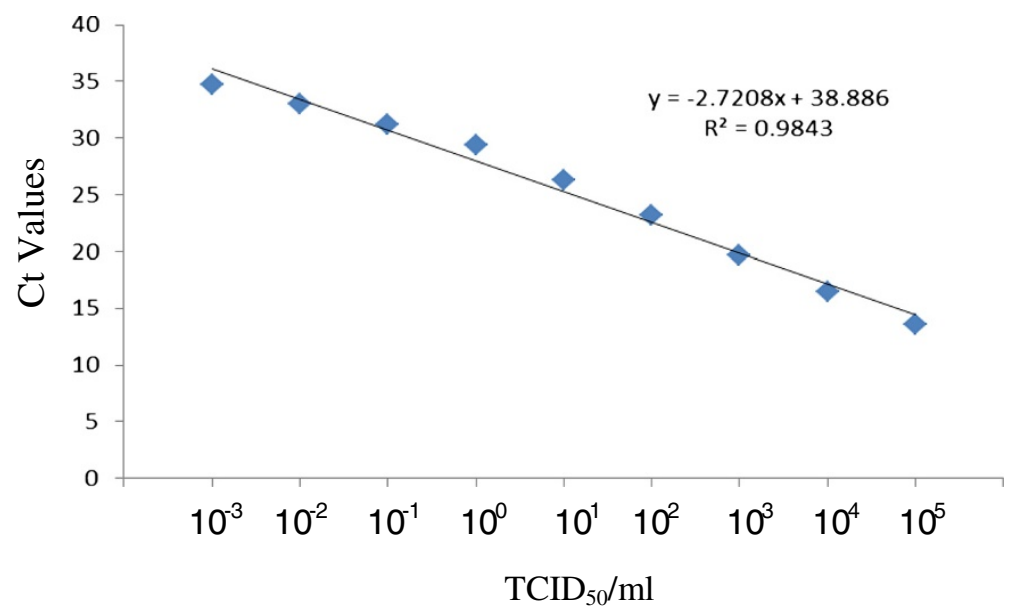

Figure 4 Sensitivity of the real time RT-PCR based on serially diluted cell culture grown PPRV. (a) Amplification plot of PPRV (from $10^{5}$ $\mathrm{TCID}_{50} / \mathrm{ml}$ to $0.001 \mathrm{TCID}_{50} / \mathrm{ml}$ ), (b) Melting curve analysis, (c) Standard curve.

variability was assessed by testing dilutions of the plasmid DNA standard in the range of $5.11 \times 10^{7}$ to $5.11 \times$ $10^{\circ}$ copies $/ \mu$ in three different experiments. The calculated SD and CV values were, ranging from 0.17 to 1.15 and from $0.71 \%$ to $5.32 \%$, respectively [Table 2(b)].

\section{Spiking}

Spiking assay with $10^{4}$ and $10^{3} \mathrm{TCID}_{50} / \mathrm{ml}$ of cell culture infected PPRV was performed on two negative goat nasal swabs. The mean $\mathrm{Ct}$ values obtained for the spiked clinical samples and tissue culture virus were compared. Negative clinical samples spiked with known titre of
PPRV and tissue culture virus with same titre were equally well detected by the assay.

\section{Evaluation of assay on clinical samples}

To evaluate the performance of the SYBR Green-based real time RT-PCR assay for the detection of PPR virus in clinical samples, 36 samples from PPR suspected cases were analyzed. Comparison of the newly developed real time RT-PCR assay was made with gel-based conventional RT-PCR assay. Real time RT-PCR assay detected PPRV RNA in 30 (83.3\%) samples. Only 16 (44.4\%) samples were positive by $\mathrm{N}$ gene based conventional RTPCR (Table 3). 


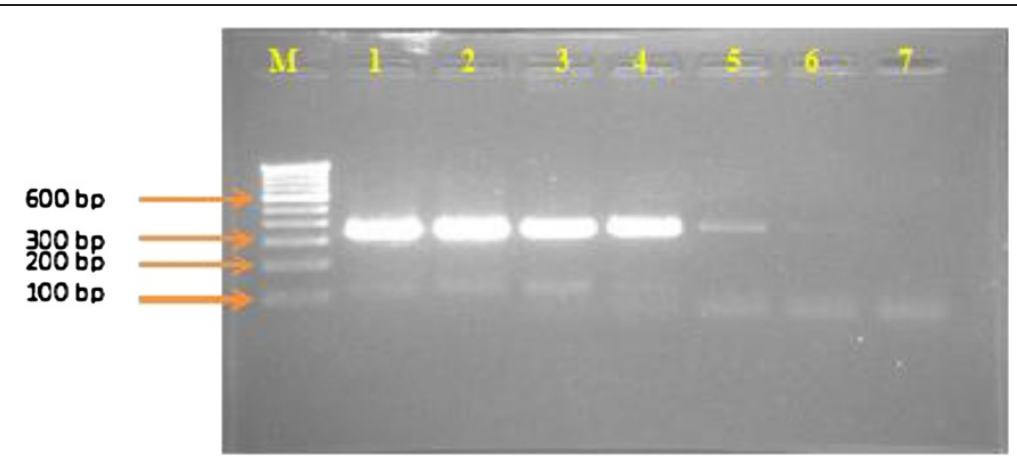

Figure 5 Sensitivity of conventional RT-PCR based on $\mathrm{TCID}_{50} / \mathrm{ml}$ by using NP3/NP4 primer pairs. Lane M-100 bp ladder; Lane-1,

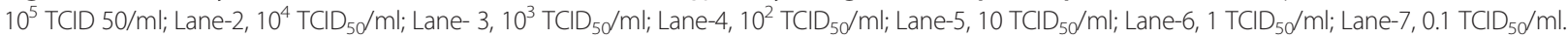
Product size, $351 \mathrm{bp}$.

\section{Discussions}

A rapid, specific and sensitive diagnostic test is a must for the accurate diagnosis and control of this economically significant disease. In this study, a two-step SYBR Green I based real time RT-PCR assay targeting the N gene of PPRV was developed and evaluated in clinical samples.

The generated standard curve can be applicable for accurate quantification of PPRV. The assay maintained linearity over seven orders of magnitude. Compared with

Table 2 Reproducibility of PPRV N gene based real time RT-PCR assay

\begin{tabular}{|c|c|c|c|c|c|}
\hline \multicolumn{6}{|c|}{ a. Intra-assay variation } \\
\hline \multicolumn{2}{|l|}{ DNA copies/ $\mu \mathrm{l}$} & \multicolumn{2}{|l|}{ Ct values } & \multirow{2}{*}{$\begin{array}{r}\text { Mean Ct } \\
10.79\end{array}$} & \multirow{2}{*}{$\frac{\text { S.D }}{0.09}$} \\
\hline $5.11 \times 10^{7}$ & 10.71 & 10.77 & 10.89 & & \\
\hline $5.11 \times 10^{6}$ & 14.52 & 14.81 & 14.75 & 14.69 & 0.15 \\
\hline $5.11 \times 10^{5}$ & 18.70 & 18.91 & 18.22 & 18.61 & 0.35 \\
\hline $5.11 \times 10^{4}$ & 21.77 & 21.75 & 21.58 & 21.70 & 0.10 \\
\hline $5.11 \times 10^{3}$ & 25.56 & 24.45 & 24.74 & 24.92 & 0.58 \\
\hline $5.11 \times 10^{2}$ & 27.07 & 27.27 & 26.89 & 27.08 & 0.19 \\
\hline $5.11 \times 10^{1}$ & 30.57 & 30.74 & 30.57 & 30.63 & 0.10 \\
\hline $5.11 \times 10^{\circ}$ & 32.52 & 33.26 & 32.59 & 32.79 & 0.41 \\
\hline \multicolumn{6}{|c|}{ b. Inter-assay variation } \\
\hline \multirow[t]{2}{*}{ DNA copies/ $\mu \mathrm{l}$} & \multicolumn{3}{|c|}{ Ct values } & \multirow[t]{2}{*}{ Mean Ct } & \multirow[t]{2}{*}{ S.D. } \\
\hline & Assay 1 & Assay 2 & Assay 3 & & \\
\hline $5.11 \times 10^{7}$ & 10.75 & 10.79 & 11.24 & 10.93 & 0.27 \\
\hline $5.11 \times 10^{6}$ & 14.84 & 14.70 & 16.17 & 15.24 & 0.81 \\
\hline $5.11 \times 10^{5}$ & 18.92 & 18.61 & 20.33 & 19.29 & 0.92 \\
\hline $5.11 \times 10^{4}$ & 22.07 & 21.7 & 23.14 & 22.30 & 0.75 \\
\hline $5.11 \times 10^{3}$ & 24.67 & 24.91 & 24.57 & 24.72 & 0.17 \\
\hline $5.11 \times 10^{2}$ & 27.42 & 27.08 & 27.61 & 27.37 & 0.27 \\
\hline $5.11 \times 10^{1}$ & 31.13 & 30.63 & 32.83 & 31.53 & 1.15 \\
\hline $5.11 \times 10^{\circ}$ & 33.12 & 32.79 & 33.74 & 33.22 & 0.48 \\
\hline
\end{tabular}

previously published real-time Taqman RT-PCR assay for the same gene target of PPRV $[7,9,10]$ the present assay was more sensitive. This improvement in sensitivity may be due to the use of SYBR Green I chemistry. This is one of the main advantages of SYBR Green I chemistry over Taqman apart from its low cost and simpler approach in designing primers and optimization procedures [15]. The newly developed assay also performed better than the RTPCR developed by Couacy-Hymann et al. [5] with respect to tissue culture infectivity titre.

The specificity of the assay was assessed in 4 different approaches: (1) by confirming the exact expected size of the amplicons in $2.5 \%$ agarose gel electrophoresis. The assay resulted in $121 \mathrm{bp}$ product; (2) by melting curve analysis. Specific amplification of the PPRV target sequence was identified by generation of consistent melting peak at $84.31 \pm 0.20$. There was no primer-dimer or non-specific products; (3) by checking the assay for cross reactivity with a range of animal viruses of clinical and genetic similarities to PPRV. There was no cross

Table 3 Comparative evaluation of clinical samples suspected of PPRV using conventional and real time RT-PCR assays

\begin{tabular}{llll}
\hline Specimen & No. & $\begin{array}{l}\text { Conventional } \\
\text { RT-PCR positive }\end{array}$ & $\begin{array}{l}\text { Real time RT-PCR } \\
\text { positive }\end{array}$ \\
\hline Ocular swab & 6 & 2 & 5 \\
Nasal swab & 9 & 7 & 9 \\
Oral swab & 3 & 1 & 2 \\
Rectal swab & 3 & 0 & 2 \\
Lymph nodes & 6 & 3 & 5 \\
Lung & 3 & 2 & 2 \\
Kidney & 1 & 0 & 1 \\
Spleen & 4 & 1 & 3 \\
Dung & 1 & 0 & 1 \\
Total & $\mathbf{3 6}$ & $\mathbf{1 6}$ & $\mathbf{3 0}$ \\
\hline
\end{tabular}


reaction (no amplification) with any one of the viruses (CDV, MV, BTV, NDV); (4) by sequence analysis of the PCR product, which showed high identity with sequences of PPRV isolates available in GenBank. These results confirmed that the specificity of the designed primers in detecting PPRV genomic material.

The reported intra- and inter-assay variations with regard to Ct values were very small and they were comparable with previously reported Taqman based real time RT-PCR assays for PPRV $[7,8]$. This suggested that the new assay can generate reproducible results. The spiking assay showed that there was no measurable inhibition in the spiked negative nasal swabs when compared to pure tissue culture virus. This indicated that the PCR performance was the same in the spiked clinical samples and the tissue culture propagated virus.

The newly developed SYBR Green I based real time RT-PCR assay was validated on clinical samples. All the samples found positive by conventional RT-PCR were confirmed by real time RT-PCR. Additional positive samples were detected by the new assay. These results indicated that the assay developed in this study showed higher sensitivity than conventional RT-PCR in detecting PPRV nucleic acids directly from clinical samples.

\section{Conclusions}

In conclusion, the two-step SYBR Green I based real time RT-PCR assay targeting the N gene of PPRV was highly sensitive, specific, reproducible and rapid for detection and quantification of PPRV nucleic acids. Since SYBR Green I is less expensive, this assay can be used in an economical manner. It can also be used as replacement for the existing Taqman RT-PCR for detection and quantitation of PPRV.

\section{Abbreviations}

BTV: Bluetongue virus; CDV: Canine distemper virus; Ct: Threshold cycle; CV: Coefficient of variation; DNA: Deoxy ribonucleic acid; MV: Measles virus; NDV: Newcastle disease virus; PPRV: Peste des petits ruminants; RPV: Rinderpest virus; RT-PCR: Reverse transcription-polymerase chain reaction; SD: Standard deviation; $\mathrm{TCID}_{50}$ : Tissue culture infective dose 50.

\section{Competing interests}

Regarding competing interests we do have neither financial competing interests nor Non-financial competing interests.

\section{Authors' contributions}

TA: Developed the proposal, carried out the research and drafted the manuscript. AT: Participated in proposal development, advised the research and helped to draft the manuscript. NDJ: Participated in the design of the study and facilitated the work. AR: Designed primers and performed the statistical analysis. All authors read and approved the final manuscript.

\section{Acknowledgment}

The authors would like to thank the Dean of Madras Veterinary College for facilitating the work. This study was funded by National Agricultural Development Project (NADP), India.

\section{Author details}

${ }^{1}$ College of Veterinary Medicine, Jigjiga University, Jijiga, Ethiopia.

${ }^{2}$ Department of Veterinary Microbiology, Madras Veterinary College, Chennai 600007, India. ${ }^{3}$ Department of Animal Biotechnology, Madras Veterinary

College, Chennai 600007, India.

Received: 12 July 2013 Accepted: 9 January 2014

Published: 14 January 2014

\section{References}

1. Gibbs EPJ, Taylor WP, Lawman MJP, Bryant J: Classification of peste des petits ruminants as the fourth member of the genus Morbillivirus. Intervirology 1979, 11:268-274.

2. Bailey D, Banyard AC, Dash P, Ozkul A, Barrett T: Full genome sequence of peste des petits ruminants virus, a member of the Morbillivirus genus. Virus Res 2005, 110:119-124.

3. Diallo A: Morbillivirus group: genome organization and proteins. Vet Microbiol 1990, 23:155-163.

4. Forsyth MA, Barrett T: Evaluation of polymerase chain reaction for the detection and characterization of rinderpest and peste des petits ruminants viruses for epidemiological studies. Virus Res 1995, 39:151-163.

5. Couacy-Hymann E, Roger F, Hurard C, Guillou JP, Libeau G, Diallo A: Rapid and sensitive detection of peste-des-petits-ruminants virus by a polymerase chain reaction assay. J Virol Methods 2002, 100:17-25.

6. Balamurugan V, Sen A, Saravanan P, Singh RP, Singh RK, Rasool TJ, Bandhyopadhyay SK: One-step multiplex RT-PCR assay for the detection of PPR virus in clinical samples. Vet Res Commun 2006, 30:566-666.

7. Bao J, Li L, Wang Z, Barrett T, Suo L, Zhao W, Liu Y, Liu C, Li J: Development of one-step real-time RT-PCR assay for detection and quantitation of pest des petits ruminants virus. J Virol Methods 2008, 148:232-236.

8. Balamurugan V, Sen A, Venkatesan G, Yadav V, Bhanot V, Bhanuprakash V, Singh RK: Application of semi-quantitative M gene-based hydrolysis probe (TaqMan) real-time RT-PCR assay for the detection of Peste des petites ruminants virus in the clinical samples for investigation into clinical prevalence of disease. Transbound Emerg Dis 2010, 10:383-395.

9. Kwiatek O, Keita D, Gil P, Fernandez-Pinero J, Clavero MA, Albina E, Libeau G: Quantitative one-step real-time RT-PCR for the fast detection of the four genotypes of PPRV. J Virol Methods 2010, 165:168-177.

10. Batten CA, Banyard AC, King DP, Henstock MR, Edwards L, Sanders A, Buczkowski H, Oura C, Barrett T: A real time RT-PCR assay for the specific detection of Peste des petits ruminants virus. J Virol Methods 2011, 171:401-404.

11. Schmittgen TD, Zakrajsek BA, Mills AG, Gorn V, Singer MJ, Reed MW: Quantitative reverse transcription-polymerase chain reaction to study mRNA decay: comparison of endpoint and real-time methods. Anal Biochem 2000, 285(2):194-200.

12. Balamurugan $V$, Sen A, Venkatesan $G$, Yadav V, Bhanot $V$, Bhanuprakash V, Singh RK: A rapid and sensitive one step-SYBR Green based semi quantitative real time RT- PCR for the detection of peste des petits ruminants virus in the clinical samples. Virologica Sinica 2012, 27(1):1-9.

13. Adams PS: Data analysis and reporting. In Real Time PCR. Edited by Dorak MT. New York, USA: Taylor \& Francis Group; 2006:40-62.

14. Reed $\amalg$, Muench $A H$ : A simple method of estimating fifty percent endpoints. Am J Hyg 1938, 27:493-497.

15. Amer HM, Almajhdi FN: Development of a SYBR Green I based real-time RT-PCR assay for detection and quantification of bovine coronavirus. Mol Cell Probes 2011, 25:101-107.

doi:10.1186/1746-6148-10-22

Cite this article as: Abera et al:: A SYBR Green I based real time RT-PCR assay for specific detection and quantitation of Peste des petits ruminants virus. BMC Veterinary Research 2014 10:22. 